\title{
Effects of Aescusan on Fibrinolytic Plasma Activity in Patients with Hypothyroidism
}

\author{
Olha Olenovych*
}

Department of Clinical Immunology, Allergology and Endocrinology, Bukovinian State Medical University, Yu.Fedkovych's str., 54, Chernivtsi, 58029, Ukraine

\begin{abstract}
The administration of Aescusan into the complex treatment program of patients with hypothyroidism was found to increase total plasma fibrinolysis almost to the control level, normalize the intensity of non-enzymatic fibrinolysis, considerably elevate the enzymatic lysis of fibrine and more effectively, as compared with standard treatment program, restore normal structure of plasma fibrinolysis.
\end{abstract}

Keywords: Aescusan, hypothyroidism, fibrinolytic activity, plasma fibrinolysis.

\section{INTRODUCTION}

The literary evidences suggest, that thyroid gland diseases are followed by phase disturbances of anticoagulant process, including fibrinolytic activity [1-4], moreover not only the character of coagulation and local fibrinolysis in the thyroid tissue itself is changed, but a functional condition of the external system of coagulanion and fibrinolysis are found to be modified as well [5-7].

At the same time, contradictions of modern literary reports concerning the character and clinical importance of hemocoagulation disorders, their dependence on the level of thyroid hormones impede the formulation of straight diagnostic and rational treatment criteria for patients with thyroid pathology.

An evident fact of a direct correlation between the severity of thyroid disease and fibrinolytic blood potential in patients with hypothyroidism substantiates the search of therapeutic methods, regulating fibrinolysis, hemodynamic and rheologic disturbances. Horse chestnut (Aesculus hippocastanum L.) preparations known to provide, besides significant vasoprotective and vasotonic, anti-inflammatory and anti-edematous, antioxidant properties, anticoagulant and fibrinolytic effects as well, were found to be perspective in this concern $[8,9]$.

Horse chestnut is one of 12 species of the genus Aesculus L., officially recognized as a source of herbal products in traditional medicine [10]. The bark, leaves, horse chestnut seed extract (HCSE) from A. hippocastanum have been used in modern medicine. HCSE is gaining wider acceptance possessing diverse pharmacological activities due to the primary active constituent - aescin. Aescin is a mixture of triterpene saponins present in two forms, $\alpha$ and $\beta$, of

*Address correspondence to this author at the Department of Clinical Immunology, Allergology and Endocrinology, Bukovinian State Medical University, Yu.Fedkovych's str., 54, Chernivtsi, 58029, Ukraine;

E-mail: olcka76@mail.ru which $\beta$-aescin is the major active component in HCSE saponin mixture $[10,11]$. The anti-inflammatory, anti-edematous, venotonic and antiangiogenic (vascular protective), anti-tumor, antioxidant, antigenotoxic, anticoagulant and fibrinolytic activities of HCSE are related to aescin [10-12]. Other constituents include bioflavonoids (quercetin and kaempferol), proanthocyanidin A2 (an antioxidant), and the coumarins fraxin and aesculin [11]. The latest ones inhibit the activity of the enzymes elastase and hyaluronidase, involved in enzymatic proteoglycan degradation. These properties make HCSE ideal for the prevention of vascular leakage.

The objective of this study was to assess therapeutic potential, mostly anticoagulant and fibrinolytic properties of HCSE preparations in case of changed thyroid status. Research strategy has been developed to investigate the effects of thyroid hormone deficiency on blood plasma fibrinolytic potential and to study the possibility of administration of HCSE preparation Aescusan (AESCUSAN DROPS, Pharma Wernigerode GmbH, Germany) in complex treatment of patients with hypothyroidism. Indicated for management of post-trombophlebitic syndrome, chronic venous insufficiency of various etiologies and its complications, thrombophlebitis, varicose veins, hemorrhoids and etc., being safe, well tolerated and acceptable to patients, AESCUSAN DROPS consist of $41.67 \mathrm{mg}$ of $\mathrm{HCSE} / \mathrm{g}$, standardised to aescin, and was administered to support conventional therapy of hypothyroidism and to improve its efficacy.

\section{MATERIALS AND METHODOLOGY}

53 patients with subcompensated primary hypothyroidism, aged between 14 and 74 years, participated in this study. The verification of the diagnosis was based on thorough clinicalanamnestic and laboratory-instrumental investigations according to the criteria, proposed by the who experts committee. The duration of hypothyroidism in the examined pa- 
Table 1. Clinical Effects of Aescusan on Fibrinolytic Plasma Activity in Patients with Hypothyroidism

\begin{tabular}{|c|c|c|c|c|c|}
\hline \multirow{3}{*}{ Indices } & \multicolumn{5}{|c|}{ Group (number of examined patients) } \\
\hline & \multirow{2}{*}{$\begin{array}{l}\text { Healthy Individu- } \\
\text { als } \\
(\mathrm{n}=18)\end{array}$} & \multicolumn{2}{|c|}{$\begin{array}{l}\text { Control Group } \\
(\mathbf{n}=\mathbf{2 6})\end{array}$} & \multicolumn{2}{|c|}{$\begin{array}{l}\text { Basic Group } \\
\quad(\mathbf{n}=\mathbf{2 7})\end{array}$} \\
\hline & & $\begin{array}{l}\text { Before } \\
\text { Treatment }\end{array}$ & $\begin{array}{c}\text { After } \\
\text { Treatment }\end{array}$ & $\begin{array}{l}\text { Before } \\
\text { Treatment }\end{array}$ & $\begin{array}{c}\text { After } \\
\text { Treatment }\end{array}$ \\
\hline $\begin{array}{l}\text { Total fibrinolytic activity, mkg of azofibrin } / \mathrm{ml} \\
\text { at } 1 \text { hour }\end{array}$ & $3.24 \pm 0.15$ & $\begin{array}{l}1.78 \pm 0.05 \\
\mathrm{P}<0.001\end{array}$ & $\begin{array}{c}2.53 \pm 0.10 \\
\mathrm{P}<0.001\end{array}$ & $\begin{array}{c}1.68 \pm 0.06 \\
\mathrm{P}<0.001 \\
\mathrm{P}_{1}>0.2\end{array}$ & $\begin{array}{c}2.65 \pm 0.10 \\
\mathrm{P}<0.01 \\
\mathrm{P}_{2}>0.4\end{array}$ \\
\hline $\begin{array}{l}\text { Non-enzymatic fibrinolytic activity, mkg of } \\
\text { azofibrin/ml at } 1 \text { hour }\end{array}$ & $0.55 \pm 0.03$ & $\begin{array}{c}0.77 \pm 0.03 \\
\mathrm{P}<0.001\end{array}$ & $\begin{array}{c}0.81 \pm 0.04 \\
\mathrm{P}<0.001\end{array}$ & $\begin{array}{c}0.73 \pm 0.03 \\
\mathrm{P}<0.001 \\
\mathrm{P}_{1}>0.3\end{array}$ & $\begin{array}{c}0.49 \pm 0.03 \\
\mathrm{P}>0.1 \\
\mathrm{P}_{2}<0.001\end{array}$ \\
\hline $\begin{array}{l}\text { Enzymatic fibrinolytic activity, mkg of } \\
\text { azofibrin/ml at } 1 \text { hour }\end{array}$ & $2.69 \pm 0.15$ & $\begin{array}{c}1.01 \pm 0.03 \\
\mathrm{P}<0.001\end{array}$ & $\begin{array}{c}1.72 \pm 0.07 \\
\mathrm{P}<0.001\end{array}$ & $\begin{array}{c}0.95 \pm 0.04 \\
\mathrm{P}<0.001 \\
\mathrm{P}_{1}>0.2\end{array}$ & $\begin{array}{c}2.16 \pm 0.07 \\
\mathrm{P}<0.001 \\
\mathrm{P}_{2}<0.001\end{array}$ \\
\hline
\end{tabular}

Note: values are expressed as means \pm standard errors; $\mathrm{P}$ - significant difference in comparison with healthy individuals $(\mathrm{P} \leq 0.05)$; $\mathrm{P}_{1}-$ significant difference between patients of control and basic groups before treatment $(\mathrm{P} \leq 0.05) ; \mathrm{P}_{2}-$ significant difference between patients of control and basic groups after treatment $(\mathrm{P} \leq 0.05)$; $\mathrm{n}-$ number of patients in a group.

tients before their enrollment to the study was nearly 12 years. The severity of the disease was assessed by the degree of clinical symptoms manifestation. Since the examination of patients was carried out during their hospital treatment, individuals with mild hypothyroidism were absent among those involved into the study, and in overwhelming majority of the patients moderate $(30 \%)$ and severe $(70 \%)$ forms of the disease were diagnosed. It should be noted, that moderate severity of hypothyroidism was identified in cases of its duration to five years $(13 \%)$, whereas severe form of the disease was observed in cases of hypothyroidism duration over 10 years $(40 \%)$.

The patients for this study were divided in two groups: control group consists of 26 patients with hypothyroidism under standard treatment program for this disease and the basic group consists of 27 patients under complex treatment with administration of Aescusan 20 drops orally three times a day for 15 days. In addition, 18 healthy individuals served as a control group. The total, enzymatic, and non-enzymatic plasma fibrinolytic activities in examined subjects (TFA, EFA and NEFA respectively) were determined according to lysis of azofibrin (Simko Ltd., Ukraine) [13, 14].

Statistical variance analysis of the obtained data was performed by means of Biostat software, using paired Student's t-criterion.

\section{RESULTS AND DISCUSSION}

The study showed there is no significant difference concerning the intensity of enzymatic fibrinolysis in patients of control and basic groups before treatment (Table 1). Thus, TFA of blood plasma in patients with hypothyroidism of control group before treatment appeared to be lower of the corresponding index in healthy individuals by $45.1 \%$. Moreover, NEFA increased by $40.0 \%$, whereas the intensity of enzymatic fibrinolysis 2.7 times reduced.

After standard treatment program total intensity of plasma fibrinolysis was elevated by $42.1 \%$, remaining lower than in healthy individuals by $21.9 \%$. NEFA didn't demonstrate any significant changes, exceeding normal indices by $47.3 \%$. The intensity of enzymatic lysis of fibrin was enhanced by $70.3 \%$, however, not getting normalized, and still remaining lower than in healthy subjects by $36.1 \%$. The structure of plasma fibrinolysis in patients with hypothyroidism was mostly contributed by NEFA before as well as after treatment (Fig. 1).

TFA of blood plasma in patients with hypothyroidism of basic group was found to be lower than that in healthy individuals by $48.1 \%$, NEFA exceeded normal index by $32.7 \%$, whereas EFA was 2.8 times decreased.

After complex treatment with administration of Aescusan the total intensity of plasma fibrinolysis increased by $57.7 \%$, being only $18.2 \%$ lower as compared with that in healthy subjects. NEFA reduced by $32.9 \%$ and didn't differ from the normal rate.

The enzymatic lysis of fibrin was found to be 2.3 times higher, demonstrating lower intensity concerning the normal index only by $19.7 \%$. If before treatment the contribution of non-enzymatic fibrinolysis into TFA was elevated, after treatment the structure of plasma fibrinolysis in patients with hypothyroidism was tending to that in healthy individuals (Fig. 2).

Thus, despite opposite directions of enzymatic and non-enzymatic fibrinolysis disturbances under condition of thyroid hormone deficiency, Aescusan, used in our current study, appeared to have the ability to normalize them.

\section{CONCLUSIONS}

Total plasma fibrinolysis is markedly inhibited in patients with hypothyroidism as the result of enzymatic fibrinolysis reduction, whereas low-effective non-enzymatic lysis of fibrin, on the contrary, increases, changing the structure of plasma fibrinolysis. The above mentioned changes are observed even after standard course of hospital treatment. Administration of Aescusan into the complex treatment of pa- 


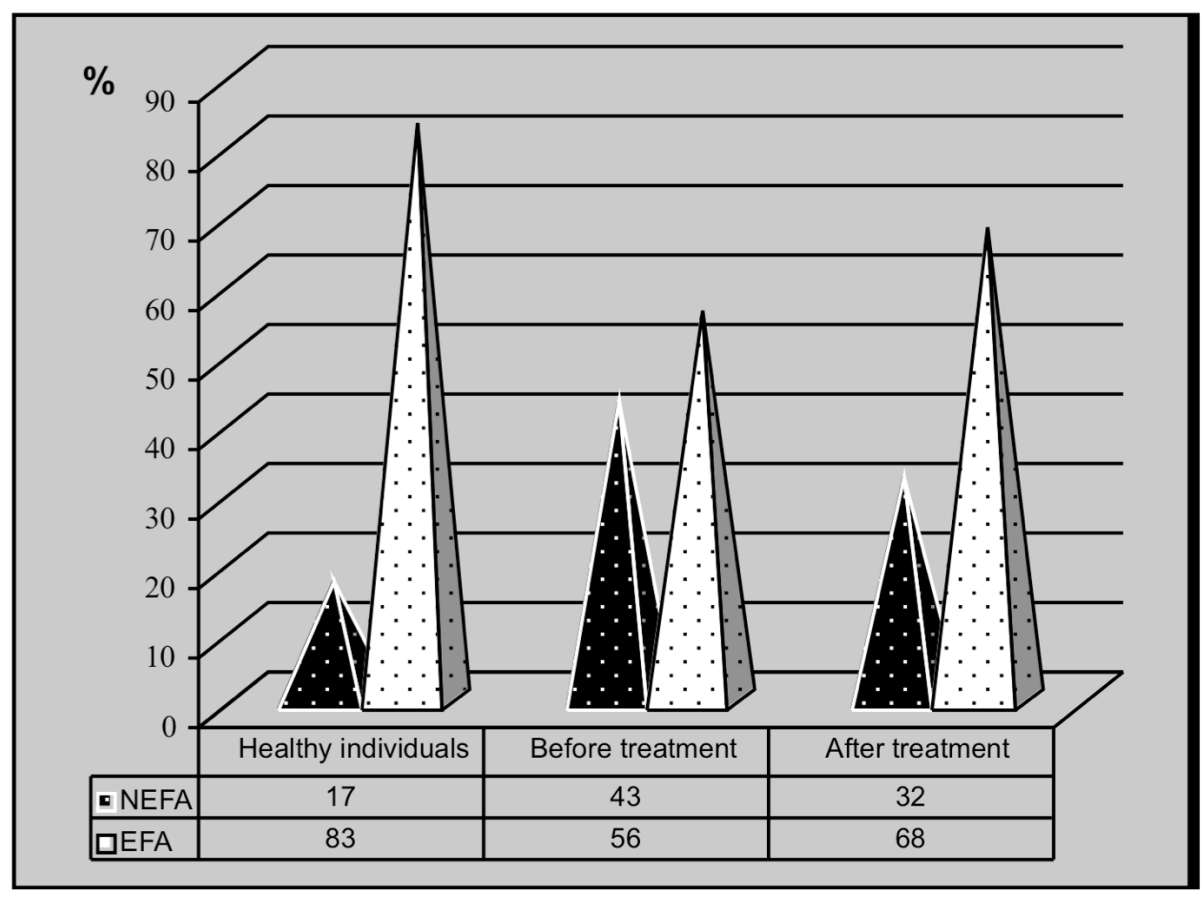

Fig. (1). Structure of plasma fibrinolysis in patients with hypothyroidism of control group (\% of TFA).

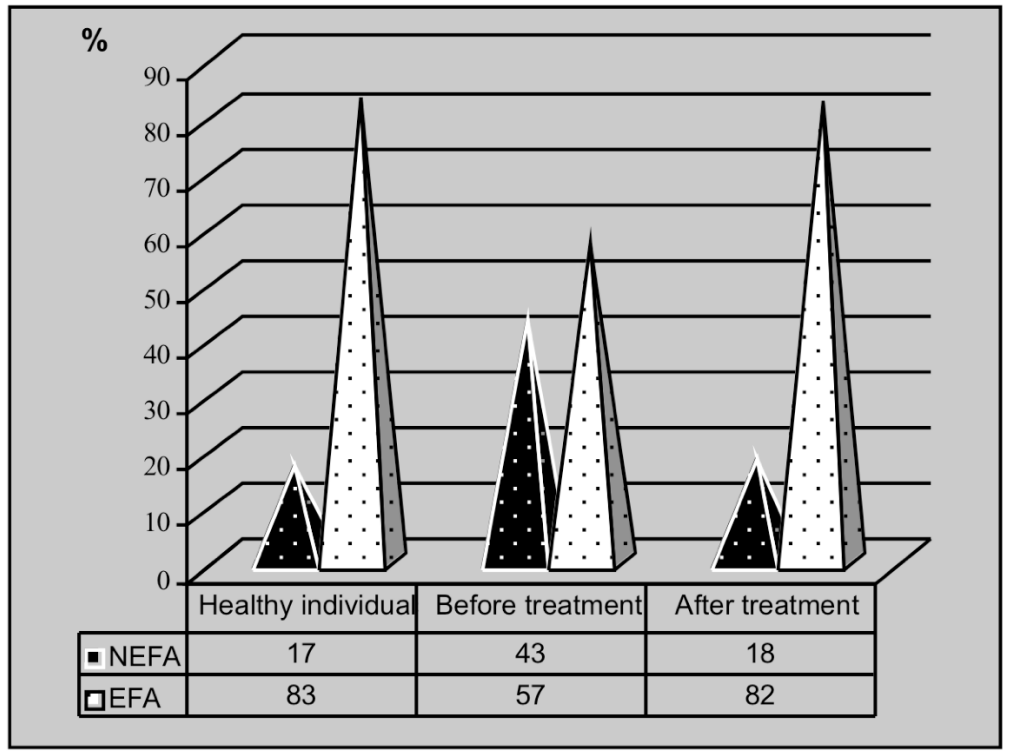

Fig. (2). Structure of plasma fibrinolysis in patients with hypothyroidism of basic group (\% of TFA).

tients with hypothyroidism promotes the increase of total plasma fibrinolysis almost up to the control level, normalizes the intensity of non-enzymatic fibrinolysis, significantly elevates enzymatic fibrinolytic activity and resumes normal structure of plasma fibrinolysis more effectively as compared with standard treatment program.

\section{ABBREVIATIONS}
EFA
$=$ Enzymatic fibrinolytic activity
HCSE
$=$ Horse chestnut seed extract

NEFA $\quad=$ Non-enzymatic fibrinolytic activity

TFA $=$ Total fibrinolytic activity

\section{REFERENCES}

[1] Alborov, R.G. The state of lipid peroxidation and hemostasis in hyper-and hypothyroidism in the experiment. TSMA, 2000, 9(1), 416.

[2] Byshevsky, A.S. The role of the thyroid gland in the regulation of hemostasis; Medical Book, 2006.

[3] Squizzato, A.; Romualdi, E.; Büller, H.R.; Gerdes, V.E.A. Thyroid dysfunction and effects on coagulation and fibrinolysis: a systematic review. J. Clin. Endocrinol. Metab., 2007, 92(7), 2415-2420. 
[4] Cihangir, E. Coagulation and fibrinolysis in thyroid dysfunction. Endocrine, 2010, 36(1), 110-118.

[5] Volkov, A.I. Hemostasis and lipid peroxidation in hypothyroidism, caused by mercazolil. TSMA, 2001, 8(1), 136-137.

[6] Erem, C. Blood coagulation, fibrinolytic activity and lipid profile in subclinical thyroid disease: subclinical hyperthyroidism increases plasma factor X activity. Clin. Endocrinol. (Oxf), 2006, 64(3), 323329.

[7] Oliveira, M.C.; Kramer, C.K.; Marroni, C.P.; Leães, C.; Viana, L.; Roithman, S.; Schmaedecke, A.; Pereira-Lima, J.F. Acquired factor viii and von willebrand factor (afviii/vwf) deficiency and hypothyroidism in a case with hypopituitarism. Clin. Appl. Thrombosis/Hemostasis, 2010, 16(1), 107-109.

[8] Vandyshev, V.V. The ancient medicinal plant - common horse chestnut - the source of modern effective medicines. Med. Care, 2002, $5,36-38$.
[9] Lakiza, T.Y.; Omelyanenko, Z.P.; Mogireva, L.A. The study of specific properties of the preparation Venoton. Pharmacol. Bull., 2000, 11-12, 31-33.

[10] Zhang, Z.; Li, S.; Lian, X.-Y. An Overview of Genus Aesculus L.: ethnobotany, phytochemistry, and pharmacological activities. Pharm. Crops, 2010, 1, 24-51.

[11] Bombardelli, E.; Morazzoni, P.; Griffini, A. Aesculus hippocastanum L. Fitoterapia, 1996, 67(6), 483-511.

[12] Sirtori, C.R. Aescin: pharmacology, pharmacokinetics and therapeutic profile. Pharmacol. Res., 2001, 44, 183-193.

[13] Bodnar, B.M.; Kukharchuk, O.L.; Magalyas, V.M.; Penishkevich, Ya.I.; Pishak, O.V., Rogoviy, Yu.Ye., Slivka, V.I.; Shapovalov, V.P. Method of investigation of fibrinolytic tissue activity. Ukraine, Patent 30727 МПК G 01 N 33/48. -98042121; 2000; pp. 7-11.

[14] Contemporary methods of experimental and clinical investigations in central scientific laboratory of Bukovinian State Medical Academy, Chernivtsi: Bukovinian State Medical Academy, 2001.

(C) Olha Olenovych; Licensee Bentham Open.

This is an open access article licensed under the terms of the Creative Commons Attribution Non-Commercial License (http://creativecommons.org/ licenses/ by-nc/3.0/) which permits unrestricted, non-commercial use, distribution and reproduction in any medium, provided the work is properly cited. 